\title{
Tackling the Toughness of Steel Pipes Produced by High Frequency Induction Welding and Heat-Treatment
}

\author{
P. Yan ${ }^{\mathrm{a}, *}$, Ö. E. Güngör ${ }^{\mathrm{b}}$, P. Thibaux ${ }^{\mathrm{b}}$, M. Liebeherr ${ }^{\mathrm{b}}$, H. K. D. H. Bhadeshia ${ }^{\mathrm{a}}$ \\ ${ }^{a}$ Materials Science and Metallurgy, University of Cambridge, Cambridge CB2 3QZ, U.K. \\ ${ }^{b}$ ArcelorMittal Global RED Ghent, OCAS NV, Pres. J. F. Kennedylaan 3, BE-9060 Zelzate, Belgium
}

\begin{abstract}
Steel linepipes produced by high frequency induction welding can result in a low-toughness zone at the weld junction, even after a heat treatment which reaustenitises the affected region. The possible causes for low toughness are explored, including microstructure, retained austenite, inclusions and crystallographic texture. It is found that the toughness is reduced primarily by the tendency for cleavage planes of ferrite crystals to align and hence create a macroscopic plane on which cleavage can propagate easily with little resistance from grain boundaries. This mechanism suggests that an appropriate heat treatment may alter the texture sufficiently to enhance the toughness of the zone concerned.
\end{abstract}

Keywords: induction welding, linepipe, steel, toughness, texture

\section{Introduction}

High frequency induction heating is often used as a solid-state process for the welding of steel pipes [1]. The process results in high productivity, can easily be adapted to manufacture pipes with different dimensions, and does not require welding consumables [2]. The process is illustrated schematically in Fig. 1, showing that the two abutting faces of the hot-rolled steel plate are heated up during their passage through the induction coils, and pressed together by the welding rolls.

The properties following welding are less than ideal [3-7] so a post-weld induction heattreatment is used in which the weld seam is austenitised and cooled. The aims of this heat treatment include replacing the coarse microstructure associated with the welding operation with smaller prior austenite grains and fine ferritic phases, homogenising the carbon at the weld junction, and producing final microstructure which is destined for service [8]. Quality control tests including cross-weld tensile tests and cross-weld Charpy tests are carried out to establish the suitability for application $[3,8,9]$.

High frequency induction welding has been a common industrial processing method since 1960s [10]. However, not much information related to this technique and the welds it produces is available in the academic literature. In particular, the properties of induction welds, although well-characterised, are simply not understood. It follows that the methods available to control the properties are not clear. Our previous work $[6,7]$ has demonstrated that the

*Email address: py210@cam.ac.uk, Tel: 0044-(0)1223334336, Fax: 0044-(0)1223334567 
low toughness of a high frequency induction weld made from one kind of X65 steel with hydrogen induced cracking resistance is entirely caused by the crystallographically coarse microstructure even after the post-weld heat treatment. Two conventional X65 pipes welded using the induction process are investigated in the current work, the mechanical properties of which have been reported previously [11]. A selection of Charpy toughness data from X65 pipes welded using the induction process are illustrated in Fig. 2. It is evident from these data that the post-weld heat treatment does not lead to a complete recovery of the Charpy toughness at the weld junction; it is the purpose of the work presented here to determine the cause.

\section{Experimental Procedure}

The chemical compositions of the steels studied are listed in Table 1. The pipe was seam welded in a solid state induction process in which the butting edges of the pipe are pushed together while they are hot and plastic, thus giving rise to flow which expels undesirable oxides from the weld, and at the same time leads to a metallurgical bond by breaking the interfaces between the edges. The pipe is allowed to cool naturally following welding, primarily by conduction between the narrow heated region and the rest of the pipe. The induction heat-treatment of the welded region involves rapid heating to form austenite. The $A e_{3}$ temperature of a typical steel in grade X65 is around $880^{\circ} \mathrm{C}[12,13]$. The exact peak temperature is proprietary information but it is set well above $A e_{3}$. Specimens were obtained before and after the post-weld heat treatment. All the samples were cut normal to the welding direction which is parallel to the rolling direction (RD), which in turn is parallel to the pipe axis. The orientation of the pipe segment and the Charpy samples are illustrated in Fig. 3. Unless explicitly stated, most results presented in the next section were obtained from the ND-TD surface. The surface for microstructural characterisation were then ground using sand paper, polished with diamond paste and then etched with $2 \%$ nital.

A Camscan MX2600 scanning electron microscope equipped with a field emission gun and an electron back-scattered diffraction (EBSD) system was used in conjunction with HKL Channel 5 software. The orientation images were taken at an operating voltage of $25 \mathrm{kV}$, a working distance of $30 \mathrm{~mm}$ and a tilt angle of $70^{\circ}$. EBSD scans were conducted using a step size of $0.2 \mu \mathrm{m}$. All the pole figures reported here are equal area projections. Sample preparation was finished by colloidal silica polishing. This microscope also has an energy dispersive X-ray analysis (EDX) system, Inca-act, which was used for characterising inclusions.

A Philips PW1820 X-ray diffraction goniometer with $\mathrm{Cu} \mathrm{K} \mathrm{K}_{\alpha}$ radiation with a wavelength $1.5406 \AA$ was used for continuous scanning with scan step time of $12.5 \mathrm{~s}$ at the step size of $2 \theta=0.05^{\circ}$ on the weld junction.

Cross-weld microhardness measurements were carried out on the as-welded samples and the samples after post-weld heat treatment by using a Mitutoyo microhardness tester with a load of $200 \mathrm{~g}$ and dwell time of $10 \mathrm{~s}$. The microhardness was measured at $150 \mu \mathrm{m}$ intervals.

\section{Results and Discussion}

The welds made in two thicknesses of X65 steel showed similar microstructures, so the images of only one kind of weld are included in most of the cases for the sake of brevity, 
and those for the other thickness are available separately for inspection [14]. The as-welded sample can be categorised into four zones [11]: the base metal, thermomechanically affected zone, heat-affected zone and weld junction. The base metal microstructure consists of fine grains of allotriomorphic ferrite with a small amount of pearlite, as shown in Fig. 4.

The upsetting process during the welding operation leads naturally to the flow of the heated metal, which, as will be evident in micrographs presented later in the paper, is reflected in the final microstructure through the presence of banding in the steel. The structures of the thermomechanically-affected (TMAZ) and the heat-affected zones (HAZ) are illustrated at higher resolution in Fig. 5 consisting of ferrite and $\mathrm{M}-\mathrm{A}$ islands. The shape and size of the ferrite grains makes the difference in microstructure between these two domains. There is anisotropy visible in the shape of the ferrite grains in the TMAZ. It suggests that this area was not fully austenised during the welding process and the untransformed ferrite grains were deformed under the pressure to form the metal flow. The heat-affected zone in comparison has equiaxed and finer ferrite grains as a result of dynamic recrystallisation due to more severe deformation in the fully-austenised region $[15,16]$, as it has closer proximity to the weld junction. The grain size analysis (Fig. 6) was carried out on orientation images using a misorientation greater than $10^{\circ}$ to identify a grain. The M-A constituents is widely present in the weld metal and heat-affected zone [21] due to the rapid cooling and possible segregations of carbon and other alloy elements involved during the process.

The microstructure at, and adjacent to the weld junction consists of a mixture of grain boundary allotriomorphic ferrite, Widmanstätten ferrite, and $\mathrm{M}-\mathrm{A}$ islands, Fig. 7. The austenite grains here are expected to be coarser, which will be confirmed by orientation imaging later. It is well-known that coarse austenite grains favour the formation of Widmanstätten ferrite [17-19]. In the middle of the weld junction, the $\mathrm{M}-\mathrm{A}$ islands are aligned along the normal direction (Fig. 7b) throughout the wall-thickness except within $1 \mathrm{~mm}$ to both the inner and outer surfaces. These strings of $\mathrm{M}-\mathrm{A}$ islands are normally found along the prior austenite grain boundaries [20-22] which on the fusion surface do not have much mobility under impact from two abutting edges on both sides.

The post-weld heat treatment significantly unifies the microstructure of the affected region. At the location of original weld junction and its near vicinity the sample showed a ferrite-pearlite microstructure (Fig. 8a and b). Figure 8b revealed clearly that the strings of $\mathrm{M}-\mathrm{A}$ islands on the weld junction turned into pearlite. The metal flow traces persisted besides the weld junction (Fig. 8c-e).

The distributions of microhardness of the as-welded samples and heat-treated samples are shown in Fig. 9. The origin of the $x$-axis corresponds to the centre of the weld junction. The post-weld heat treatment, as expected, leads to an overall decrease in the hardness in both pipes and the abrupt drop of hardness at the weld junction in the as-welded stage has been removed, which supports that the microstructure has been made more uniform and the extent of decarburisation has been reduced.

The X-ray diffraction patterns (Fig. 10) of the as-welded samples revealed only a small amount of austenite, which should be contributed by those M-A islands seen in Fig. 5 and 7 . Retained austenite was absent following post-weld heat treatment, which transformed into pearlite.

The induction welding process involves the upsetting of the two parts being joined in order to expel a certain amount of steel; this helps make a clean joint free from inclusions. 
Nevertheless, the possibility of oxides at the weld junction was investigated using extensive scanning electron microscopy together with EDX. RD-TD surfaces with the weld junction in the middle were prepared for investigation of inclusions. In the heat-treated segment with the size of $10 \mathrm{~mm}$ along the rolling direction from the pipe with $8.6 \mathrm{~mm}$ wall-thickness, inclusions were revealed on the RD-TD surfaces near the outer and inner surfaces and at the mid-thickness of the pipe as shown in Fig. 11. Most of these inclusions aligned along the weld junction possess compositions consistent with manganese and silicon oxides (Table 2). During the welding process, these oxides formed by heating the edges of the steel plate and did not get expelled out by the joining. Post-weld heat treatment was not able to attack the inclusions. At the mid-thickness, several aluminium and calcium rich oxides were also found (Fig. 11b and Table 2), but the number and distribution are not as substantial as those manganese and silicon oxides. Fractography carried out on the tested Charpy sample from the weld junction also revealed the inclusions with similar compositions of manganese and silicon oxides, Fig. 11d and Table 2; the inclusions clearly are detrimental to the toughness of the weld.

Surprisingly when the same investigation on the RD-TD surfaces was carried out on the heat-treated weld from the pipe with $14.8 \mathrm{~mm}$ wall-thickness, no inclusion was found. Three pairs of Charpy fracture surfaces from the weld junction tested at $-40^{\circ} \mathrm{C}$ were also examined. No clue of inclusion initiating fracture was discovered. These three Charpy samples all showed an absorbed energy comparable to what the sample illustrated in Fig. 11d gave. It might be the fact that the manganese and silicon oxides were not present continuously along rolling direction, which is the welding direction, but it is more likely that there is another factor also playing an important role in causing the low toughness at the weld junction. In the case of the pipe with $8.6 \mathrm{~mm}$ wall-thickness, the inclusions in Fig. 11d was found on the tested sample showing the absorbed energy of $6 \mathrm{~J}$, which is lower than the mean value as shown in Fig. 2. The highest value of absorbed energy from the tests with the same condition is 44 $\mathrm{J}$ [11]. This scatter supports the discontinuity of the inclusions along the weld. However, it is not explained that even the highest value of absorbed energy at the weld junction is still much lower than the result from the base metal at the same testing temperature, which is above 120 J, Fig. 2.

Continuous scans on the ND-TD surface along the transverse direction near the outer and inner surfaces, and at the mid-thickness of both pipes from base metal to the weld junction have been carried out by the EBSD technique. Figure 12a shows ferrite orientation images from base metal, which is $4 \mathrm{~mm}$ away from the weld junction on the as-welded sample. The crystal orientations are not uniformly distributed, as illustrated by the $\{100\}$ pole figure (Fig. 12c), but the ferrite grains have a large range of orientations. More importantly, there is no accumulation of $\{100\}$ poles around transverse direction. This means there is few $\{100\}$ planes parallel or nearly parallel to the ND-RD surface, which is the fracture surface of the Charpy samples in this study, as shown in Fig. 3. The $\{100\}$ plane is the cleavage plane of BCC iron crystal $[23,24]$, so a low density of $\{100\}$ planes parallel to ND-RD surface should lead to a higher fracture energy. Figure $12 \mathrm{~b}$ shows the scattered grains having their $\{100\}$ planes oriented within $10^{\circ}$ to the fracture surface, which represents only $3 \%$ of the area in Fig. 12a. The results are consistent with the base-metal toughness data illustrated in Fig. 2. Conversely, a high density of $\{100\}$ planes parallel to the fracture surface leads to a lower toughness. As illustrated in Fig. 12f, the as-welded weld junction is strongly textured with 
only one main orientation, and there is high concentration of $\{100\}$ poles around the transverse direction. Some $19 \%$ of the area in Fig. 12d is occupied by clusters of grains oriented for easy fracture, Fig. 12e, which accounts for the poor toughness of this region, Fig. 2. The intensity of the weld-junction texture decreased following post-weld heat treatment, as illustrated in Fig. 12i, but the accumulation of $\{100\}$ planes around transverse direction was not diminished. Bear in mind that the as-welded junction is constituted of both shear products (Widmanstätten ferrite and $\mathrm{M}-\mathrm{A}$ islands) and diffusional products (allotriomorphic ferrite) from the transformation, so part of the prior austenite grain structure formed during the welding process was reproduced by the rapid heating of the induction heat treatment due to the austenite memory effect [25]. Fig. 12h shows that grains possessing cleavage planes within $10^{\circ}$ to the fracture surface still take up $10 \%$ of the area Fig. $12 \mathrm{~g}$. This explains why the improvement of toughness on the weld-junction by post-weld heat treatment is not as much as being comparable to the base metal, Fig. 2 .

Table 3 gives a general view of the area percentage of $\{100\}$ planes similarly oriented with the fracture surface for both kinds of pipes. Each value in the table is obtained from an EBSD scan of an area with the same size of Fig. $12 \mathrm{a}$, d or g, i.e., $242.8 \times 100 \mu^{2}$. The width of the scan is consistent with the radius of the $\mathrm{V}$-notch. For both kinds of pipes, base metal has the lowest density of cleavage planes oriented for easy fracture, while the as-welded junction has the highest. After post-weld heat treatment, the density decreased but did not go down to the base metal level.

Three angles between three $\{100\}$ planes and the ND-RD surface of all the grains from the scanned areas of base metal and heat-treated weld junction respectively were calculated by using the Euler angles obtained by EBSD technique. The minimum of the three angles for each grain is selected to plot the distributions shown in Fig. 13, with each line representing the same size of the areas either in base metal or in weld junction. For both pipes, firstly there is higher fraction of grains with unfavourably oriented cleavage planes in the heat-treated weld junction compared to the base metal (Fig. 13a and b), which makes the former more prone to cleavage. Secondly, base metal has higher fraction of grains with their cleavage planes oriented in the angles between 40 and $50^{\circ}$ to the fracture surface, which is the favourable orientation against the fracture. Besides, substantially larger number of grains contribute to this range in the base metal than in the heat-treated weld junction (Fig. 13c and d); since the former has finer grains, which is also noticeable in the orientation images ( $c f$. Fig. 12a and $\mathrm{g}$ ). Larger number of grains oriented against the fracture produce more deviation for the crack propagation across more grain boundaries, which leads to higher absorbed energy and toughness.

\section{Summary}

It is found that the high frequency induction welded junctions from two X65 grade steel pipes with different wall-thickness possess unsatisfactory toughness after post-welding heat treatment, even though the microstructure across the weld was uniform and there is no decarburisation and remaining austenite after post-welding heat treatment. Meticulous investigation has then identified three causes of the weakness: the existence of non-metallic inclusions, crystallographic texture, and larger grain size. Persistence of manganese and silicon rich oxides have a negative effect on the mechanical properties of the weld, but these inclusions 
only exist occasionally along the welding direction. Low toughness in the weld-junction is substantially related to the grain orientation favouring fracture. This 'bad' texture is produced during the welding process. Reaustenitisation during the post-welding heat treatment reduces the intensity of the texture but dose not alter it. The heat-treated weld-junction was also found to have coarser grains compared to the base metal, which helps to enlarge the difference in toughness between the two samples.

More carefully designed post-welding heat treatment should be able to modify the crystallographic texture in the weld junction. Some experiments carried out in the thermomechanical simulator resulted in more randomly textured and finer microstructure compared to the industrial process [14]. The frequency of inclusions can be reduced by expelling more material from the weld junction during the induction welding process. Employing more force onto the pressure rolls or a redesign of the layout in the welding mill is recommended to eject the material uniformly along the rolling/welding direction. Both methods need systematic calculations using actual data obtained on the production line.

\section{Acknowledgements}

The authors are grateful to ArcelorMittal for financial and technical support, and would like to thank Eric Hivert (retired from Arcelor and self-employed now), and David Quidort from ArcelorMittal Commercial FCE for helpful discussions. They also thank Professor A. L. Greer for the provision of laboratory facilities at the University of Cambridge.

\section{References}

[1] K. D. Houghton. Welded linepipe for offshore sour service applications. Journal of Offshore Technology, 3:46-48, 1995.

[2] W. C. Rudd, G. A. Smith, E. D. Oppenheimer, R. E. Somers, A. F. Manz, and D. D. Rager. Welding Handbook, volume 3, chapter High Frequency Welding, page 156. American Welding Society, 7th edition, 1982.

[3] J. G. Williams, C. R. Killmore, F. J. Barbaro, J. Piper, and Fletcher. High strength ERW linepipe manufacture in Australia. Mater. Forum, 20:13-28, 1996.

[4] N. Pradhan, N. Banerjee, B. B. Reddy, S. K. Sahay, D. S. Basu, P. K. Bhor, S. Das, and S. Bhattyacharya. Control of defects during continuous casting of line pipe (api) quality steels. Scandinavian J. of Metall., 34:232-240, 2005.

[5] C. Yu. Metallographic examination evaluation criteria and control for erw pipe production. Tube International, pages 153-155, 1996.

[6] P. Yan, Ö. E. Güngör, P. Thibaux, and H. K. D. H. Bhadeshia. Crystallographic texture of induction-welded and heat-treated pipeline steel. Advanced Materials Research, 8991:651-656, 2010.

[7] P. Yan, Ö. E. Güngör, P. Thibaux, and H. K. D. H. Bhadeshia. Induction welding and heat treatment of steel pipes: evolution of crystallographic texture detrimental to toughness. Science and Technology of Welding and Joining, 15(2):137-141, 2010. 
[8] E. Treiss. Induction Annealing of welds in the fabrication of high-frequency induction welded steel line pipes. 3R International, 20(11):627-630, 1981.

[9] R. R. Preston. A review of high strength, low alloy steel metallurgy in Europe. In A. B. Rothwell and J. M. Gray, editors, Welding of HSLA (microalloyed) structural steels, pages 24-25, Ohio, USA, 1978. American Society for Metals.

[10] E. Runte. Continuous high-frequency induction tube welding. The Brown Boveri Review, 55(3):113-118, 1968.

[11] Ö. E. Güngör, P. Yan, P. Thibaux, M. Liebeherr, H. K. D. H. Bhadeshia, and D. Quidort. Inverstigations into microstructre-toughness relation in high frequency induction welded pipes. In Proceedings of the 8th international pipeline conference, IPC2010-31372, Calgary, Alberta, Canada, 27th Sep.-1st Oct. 2010.

[12] M. Militzer, R. Pandi, and E.B. Hawbolt. Ferrite nucleation and growth during continuous cooling. Metall. Trans. A, 27A:1547-1556, 1996.

[13] J. Q. Wang, A. Atrens, D. R. Cousens, and N. Kinaev. Microstructure of X52 and X65 pipeline steels. Journal of Materials Science, 34:1721-1728, 1999.

[14] P. Yan. High frequency induction welding and post-welding heat treatment of steel pipes. PhD thesis, University of Cambridge, 2011. www.msm.cam.ac.uk/phasetrans/2011/Pei_thesis.pdf.

[15] G. R. Speich, L. J. Cuddy, C. R. Gordon, and A. J. DeArdo. Formation of ferrite from control-rolled austenite. In A. R. Marder and J. I. Goldstein, editors, Phase Transformations in Ferrous Alloys, pages 341-389, Warrendale, Pennsylvania, USA, 1984. TMS-AIME.

[16] I. Tamura. Some fundamental steps in thermomechanical processing of steel. Trans. ISIJ, 27:763-779, 1987.

[17] R. L. Bodnar and S. S. Hansen. Effects of austenite grain size and cooling rate on Widmanstätten ferrite formation in low alloy steels. Metallurgical \& Materials Transactions A, 25A:665-675, 1994.

[18] S. Jones and H. K. D. H. Bhadeshia. Kinetics of the simultaneous decomposition of austenite into several transformation products. Acta Materialia, 45:2911-2920, 1997.

[19] S. Jones and H. K. D. H. Bhadeshia. Competitive formation of inter- and intragranularly nucleated ferrite. Metallurgical \& Materials Transactions A, 28A:2005-2103, 1997.

[20] Y. Li and T. N. Baker. Effect of morphology of martensite-austenite phase on fracture of weld heat affected zone in vanadium and niobium microalloyed steels. Mater. Sci. Technol., 26(9):1029-1040, 2010.

[21] C. L. Davis and J. E. King. Effect of cooling rate on intercritically reheated microstructure and toughness in high strength low alloy steel. Mater. Sci. Technol., 9(1):8-15, 1993. 
[22] J. H. Chen, Y. Kituta, T. Araki, M. Yoneda, and Y. Matsuda. Micro-fracture behaviour induced by M-A constituent (island martensite) in simulated welding heat affected zone of HT80 high strength low alloyed steel. Acta Metallurgica, 32:1779-1788, 1984.

[23] W. R. Tyson, R. A. Ayres, and D. F. Stein. Anisotropy of cleavage in BCC transition metals. Acta Met., 21(5):621-627, 1973.

[24] V. M. Goritskii and D. P. Khromov. Crystallographic direction of brittle transcrystalline cleavage in the ferrite of low-carbon low-alloy steels. Problemy Prochnosti, 16(6):83-88, 1984.

[25] S. T. Kimmins and D. J. Gooch. Austenite memory effect in 1Cr-1Mo-0.75V(Ti, B) steel. Metal Science, 17(11):519-532, 1983.

[26] R. K. Nichols. High frequency welding-the process and applications. Technical report, Thermatool Corporation, Connecticut, USA, April 1999.

Materials Science and Engineering: A

Volume 528, Issues 29-30, 15 November 2011, Pages 8492-8499 


\begin{tabular}{lccccc}
\hline & $\mathrm{C}$ & $\mathrm{Mn}$ & $\mathrm{Si}$ & $\mathrm{Nb}$ & $\mathrm{Al}$ \\
\hline X65 thin plate $(8.6 \mathrm{~mm})$ & 0.055 & 1.5 & 0.2 & 0.044 & 0.023 \\
X65 thick plate $(14.8 \mathrm{~mm})$ & 0.064 & 1.5 & 0.21 & 0.049 & 0.026 \\
\hline
\end{tabular}

Table 1: Steel chemical compositions (wt\%).

\begin{tabular}{lllllllll}
\hline & $\mathrm{C}$ & $\mathrm{O}$ & $\mathrm{Al}$ & $\mathrm{Si}$ & $\mathrm{Ca}$ & $\mathrm{Ti}$ & $\mathrm{Mn}$ & $\mathrm{Fe}$ \\
\hline Fig. 11a & - & 31.43 & 2.04 & 16.46 & 0.59 & 1.48 & 45.07 & 2.92 \\
& & \pm 0.31 & \pm 0.1 & \pm 0.19 & \pm 0.09 & \pm 0.12 & \pm 0.36 & \pm 0.27 \\
Fig. 11b & 4.25 & 30.16 & 2.67 & 14.34 & 0.59 & 1.34 & 38.78 & 7.87 \\
& \pm 0.4 & \pm 0.33 & \pm 0.1 & \pm 0.19 & \pm 0.09 & \pm 0.13 & \pm 0.39 & \pm 0.31 \\
Fig. 11b & 2.84 & 33.78 & 26.92 & 1.25 & 11.36 & - & - & 23.85 \\
(cir- & \pm 0.4 & \pm 0.33 & \pm 0.24 & \pm 0.08 & \pm 0.17 & & & \pm 0.34 \\
cles) & & & & & & & & \\
Fig. 11c & 3.97 & 34.97 & 2.33 & 18.63 & 0.49 & 1.83 & 35.88 & 1.9 \\
& \pm 0.41 & \pm 0.35 & \pm 0.11 & \pm 0.22 & \pm 0.08 & \pm 0.13 & \pm 0.38 & \pm 0.25 \\
Fig. 11d & - & 31.38 & 1.42 & 16.48 & 0.41 & 0.96 & 46.06 & 3.28 \\
& & \pm 0.26 & \pm 0.08 & \pm 0.13 & \pm 0.05 & \pm 0.07 & \pm 0.24 & \pm 0.15 \\
\hline
\end{tabular}

Table 2: Compositions for the inclusions (wt $\%$ with $\sigma$ ) by EDX.

\begin{tabular}{lccc}
\hline \multirow{2}{*}{8.6 mm wall-thickness } & \multirow{2}{*}{ Base metal } & \multicolumn{2}{c}{ Weld junction } \\
& & As-welded & Heat-treated \\
\hline Near outer surface & 2 & 12 & 9 \\
At mid-thickness & 2 & 24 & 10 \\
Near inner surface & 2 & 12 & 7 \\
Average & 2 & 16 & 8.7 \\
\hline \multirow{2}{*}{ 14.8 mm wall-thickness } & Base metal & \multicolumn{2}{c}{ Weld junction } \\
& & As-welded & Heat-treated \\
\hline Near outer surface & 3 & 19 & 10 \\
At mid-thickness & 3 & 12 & 10 \\
Near inner surface & 4 & 14 & 7 \\
Average & 3.3 & 15 & 9 \\
\hline
\end{tabular}

Table 3: Area percentage of grains containing $\{100\}_{\alpha}$ planes within $10^{\circ}$ to the RD-ND surface. 


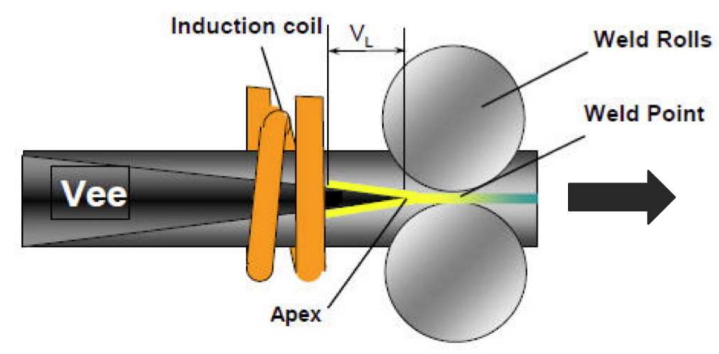

Figure 1: Schematic representation of the thermomechanical processes that lead to the formation of a joint during high-frequency induction welding. Adapted from [26].
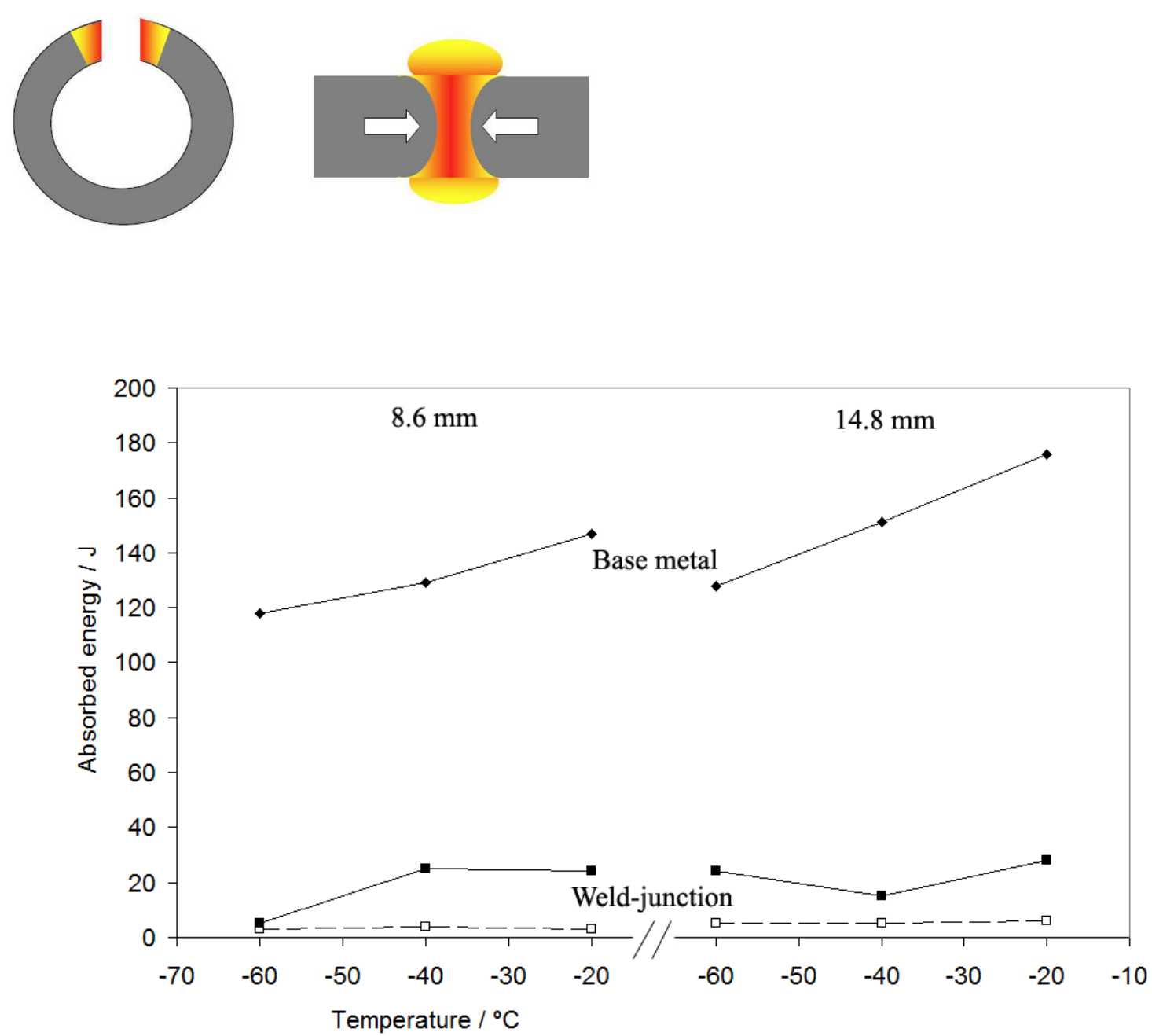

Figure 2: The low temperature Charpy toughness the high-frequency induction welded and heat-treated X65 pipes [11]. The dashed lines are measurements at as-welded state. 


\section{Pipe segment}

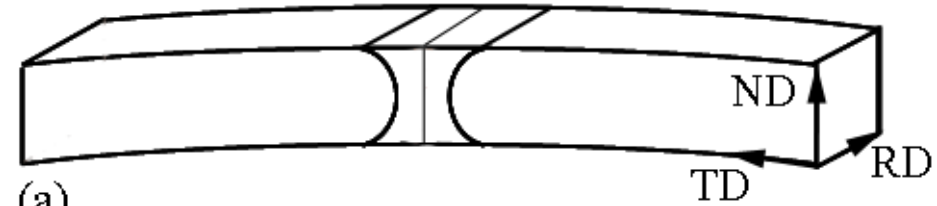

(a)

Machined Charpy sample

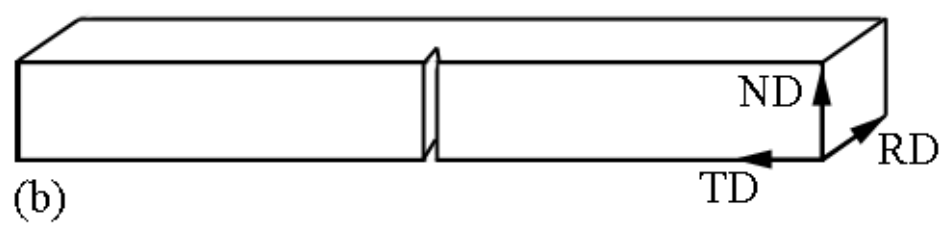

Figure 3: (a) The orientation of the pipe segment relative to steel processing directions. (b) Orientation of Charpy specimen.

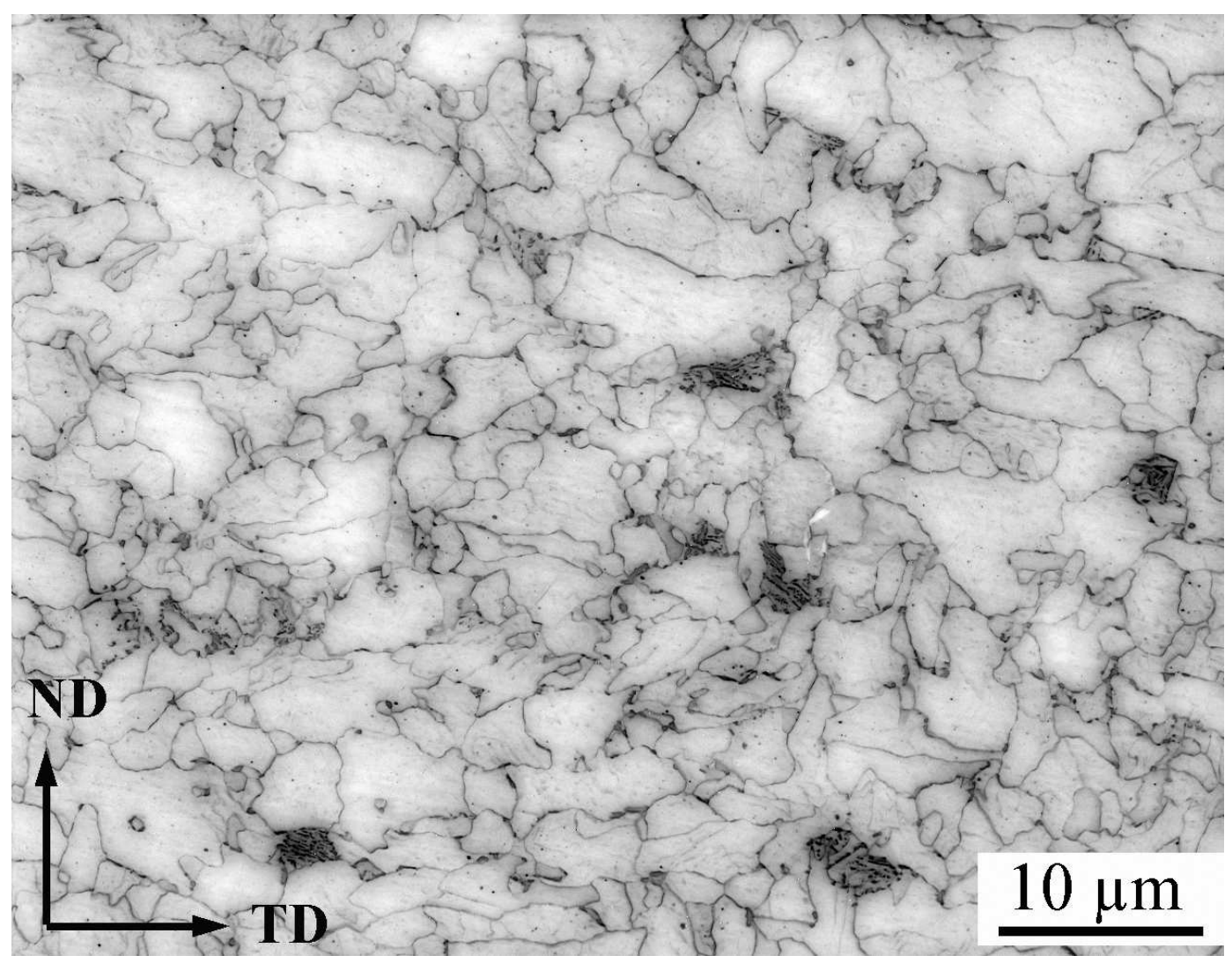

Figure 4: Microstructure of base metal of the pipe with $8.6 \mathrm{~mm}$ wall-thickness. 

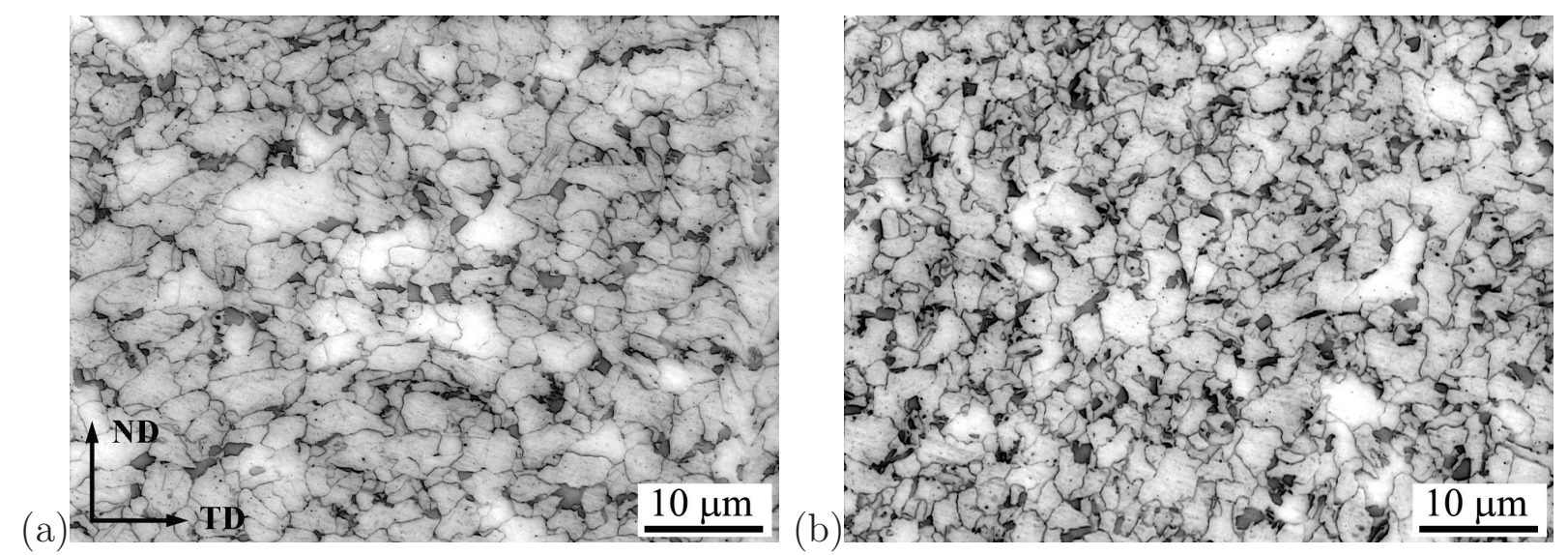

Figure 5: As-welded sample from X65 pipe with $8.6 \mathrm{~mm}$ wall-thickness. (a) Thermomechanically affected zone. (b) Heat-affected zone.

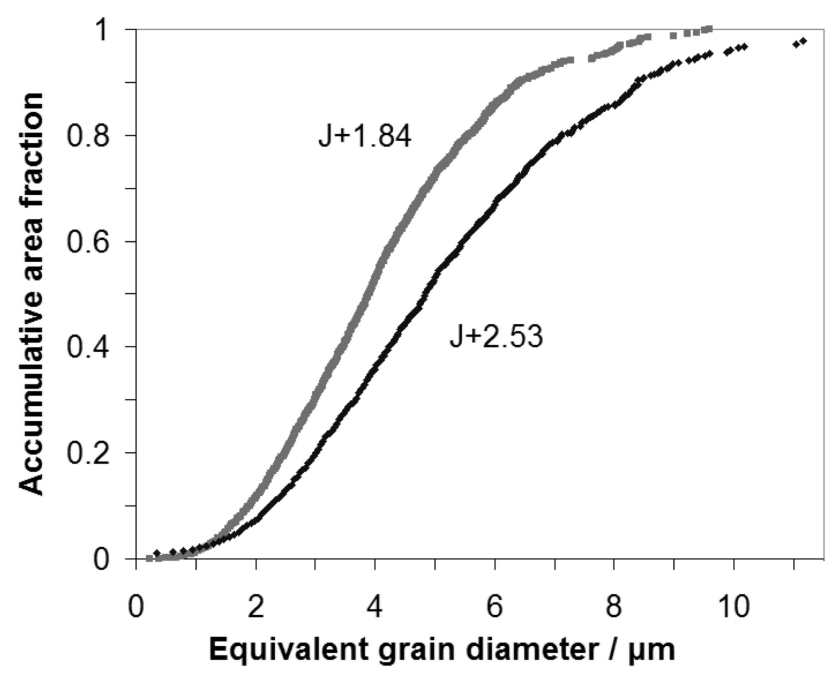

Figure 6: Crystallographic grain size analysis of the as-welded sample near the outer surface of the $8.6 \mathrm{~mm}$ thick X65 pipe, determined from an area $243 \times 100 \mu^{2}$. The locations 1.84 and $2.53 \mathrm{~mm}$ from the weld junction correspond to the HAZ and TMAZ respectively.
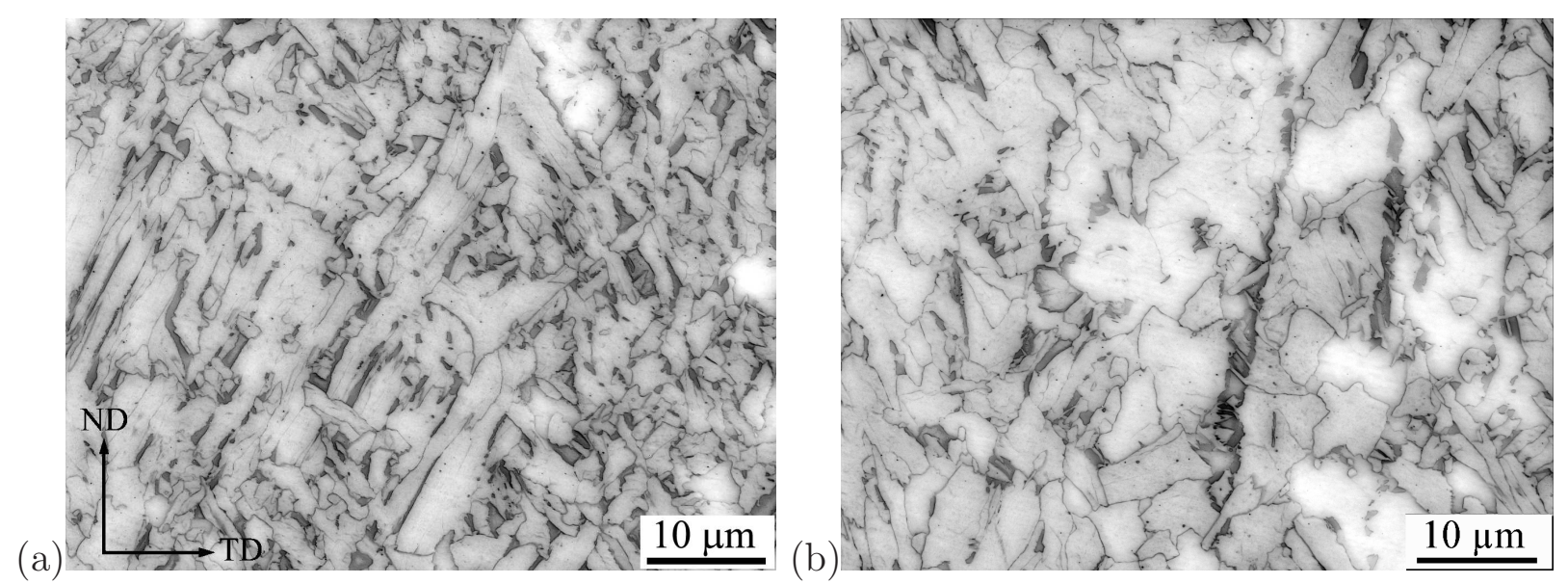

Figure 7: Microstructure (a) adjacent to and (b) at the weld junction in the as-welded pipe with $8.6 \mathrm{~mm}$ wall-thickness. 

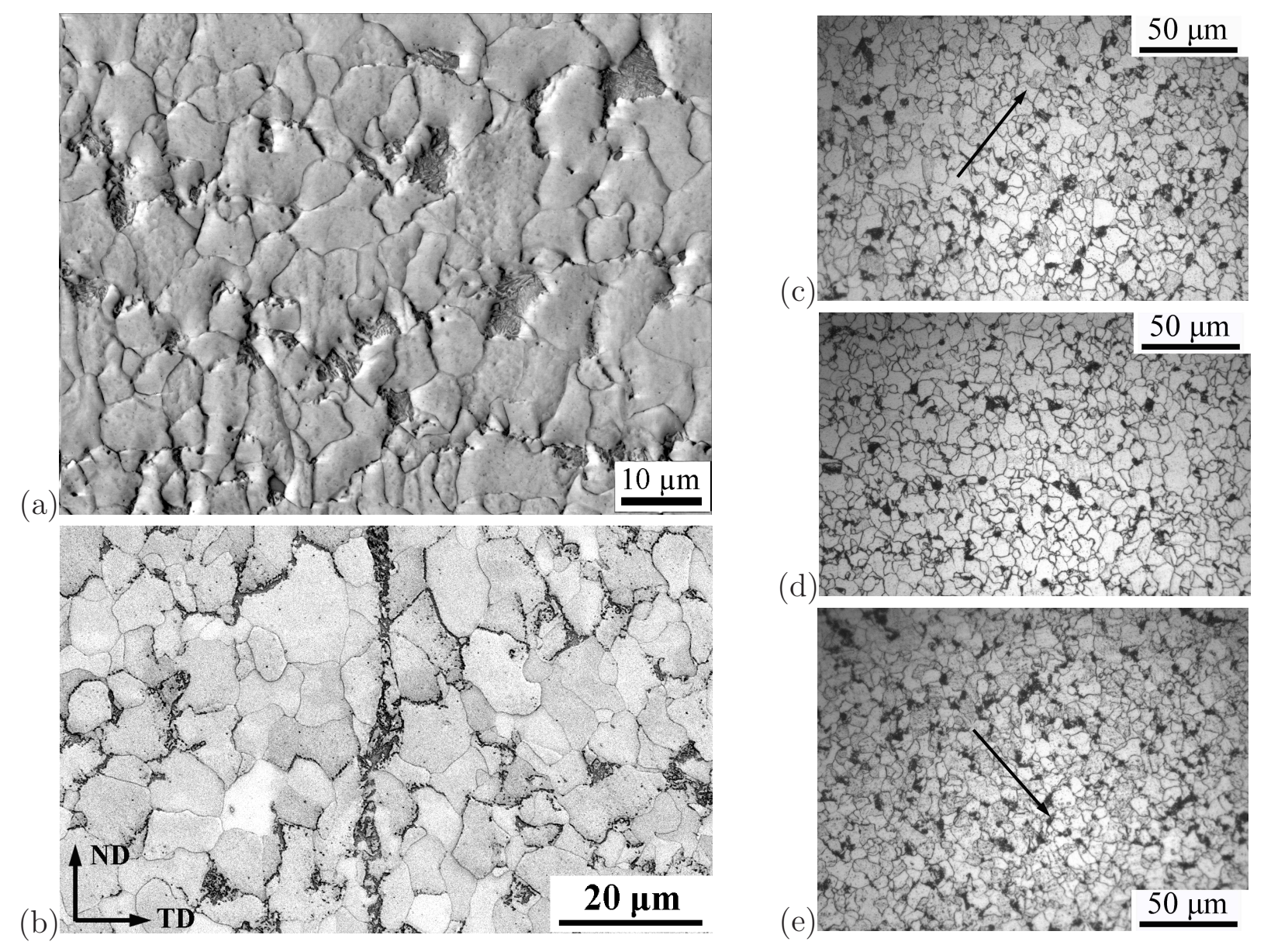

Figure 8: Scanning electron micrographs of the heat-treated pipe with $8.6 \mathrm{~mm}$ wall-thickness. (a) At the vicinity of the original weld junction location. (b) On the location. Optical micrograph showing the trace of the metal flow on one side of the weld junction: (c) near outer surface, (d) at the mid-thickness and (e) near inner surface of the pipe. 


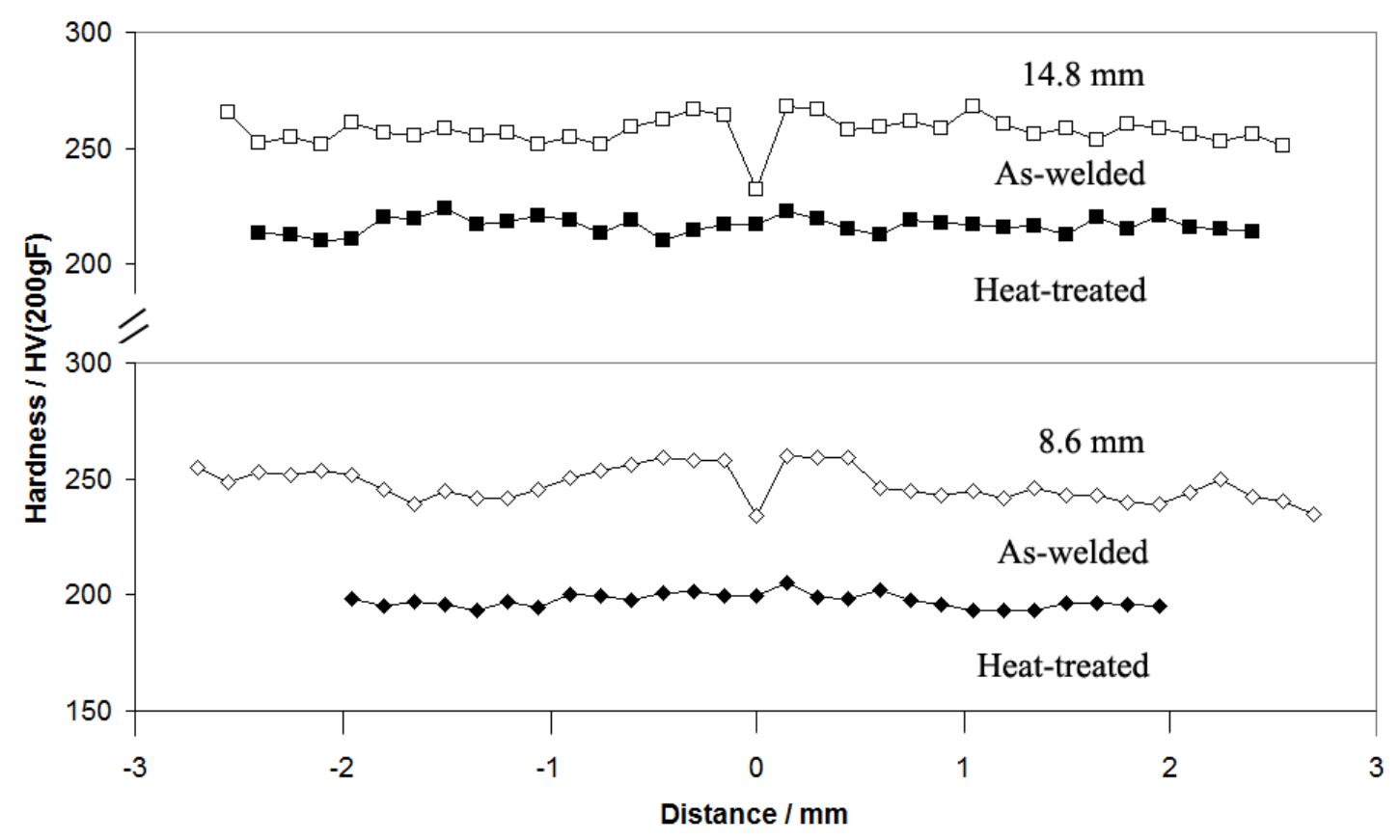

Figure 9: Cross-weld microhardness measurements.

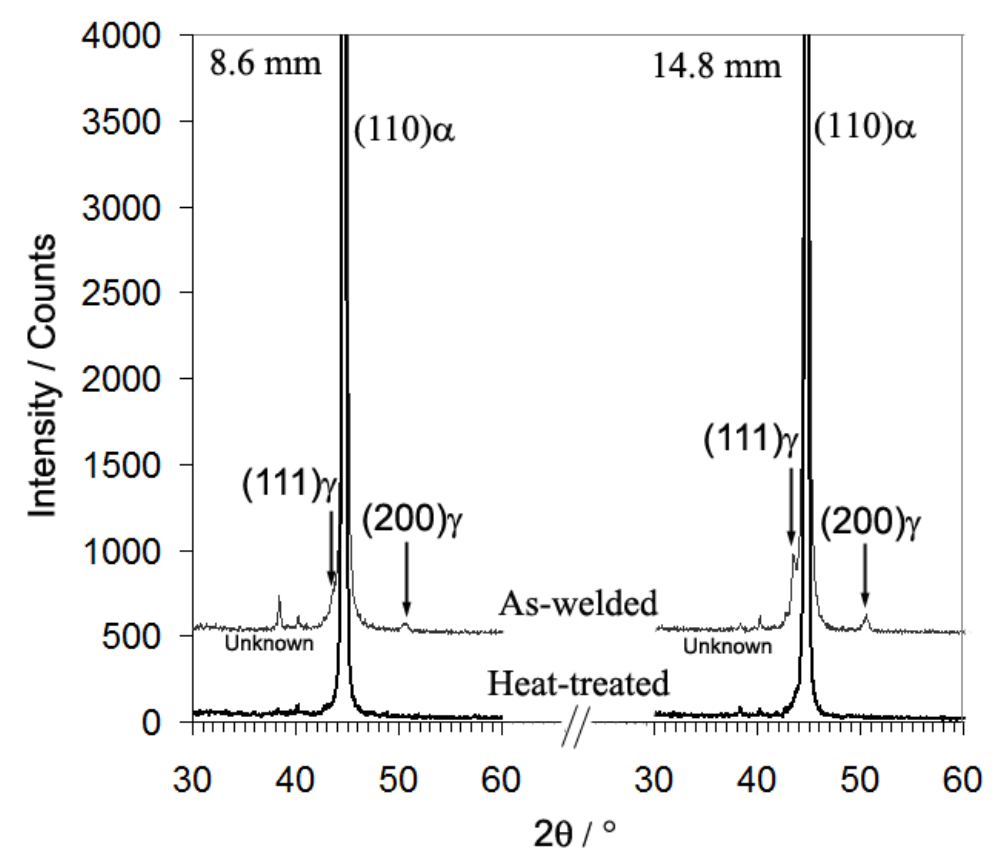

Figure 10: X-ray diffraction patterns. The vertical and horizontal scales have been truncated for clarity. The vertical axis in fact extends to 40000 counts and the horizontal scan was maintained to $150^{\circ}$. 

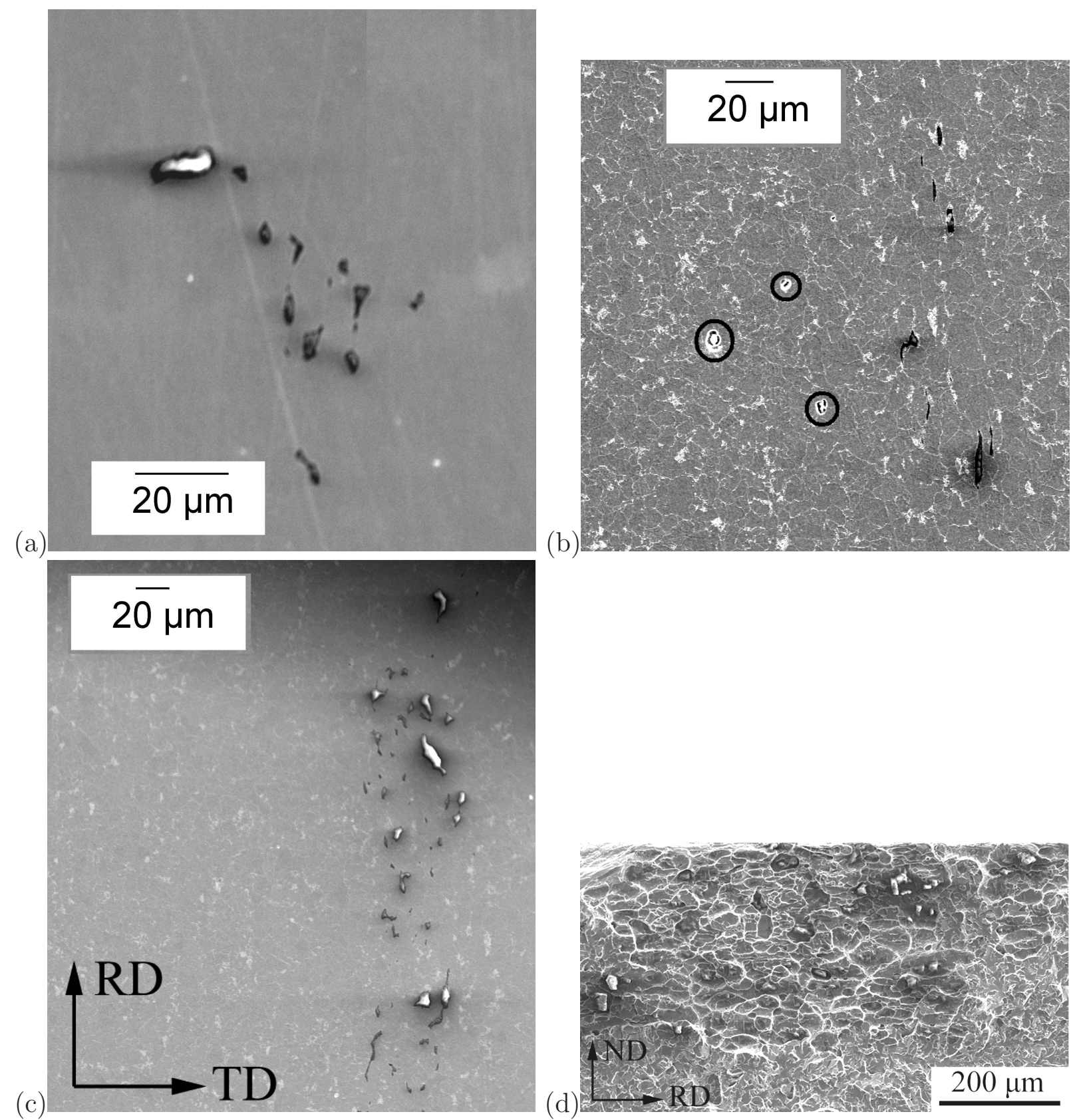

Figure 11: Scanning electron micrographs of the inclusions in the weld junction of the heat-treated segment of pipe with $8.6 \mathrm{~mm}$ wall-thickness (a) Near the outer surface. (b) At mid-thickness. (c) Near the inner surface. (d) Fracture surface at weld junction after post-weld heat treatment from the pipe with $8.6 \mathrm{~mm}$ wall-thickness, tested at $-40^{\circ} \mathrm{C}$ 


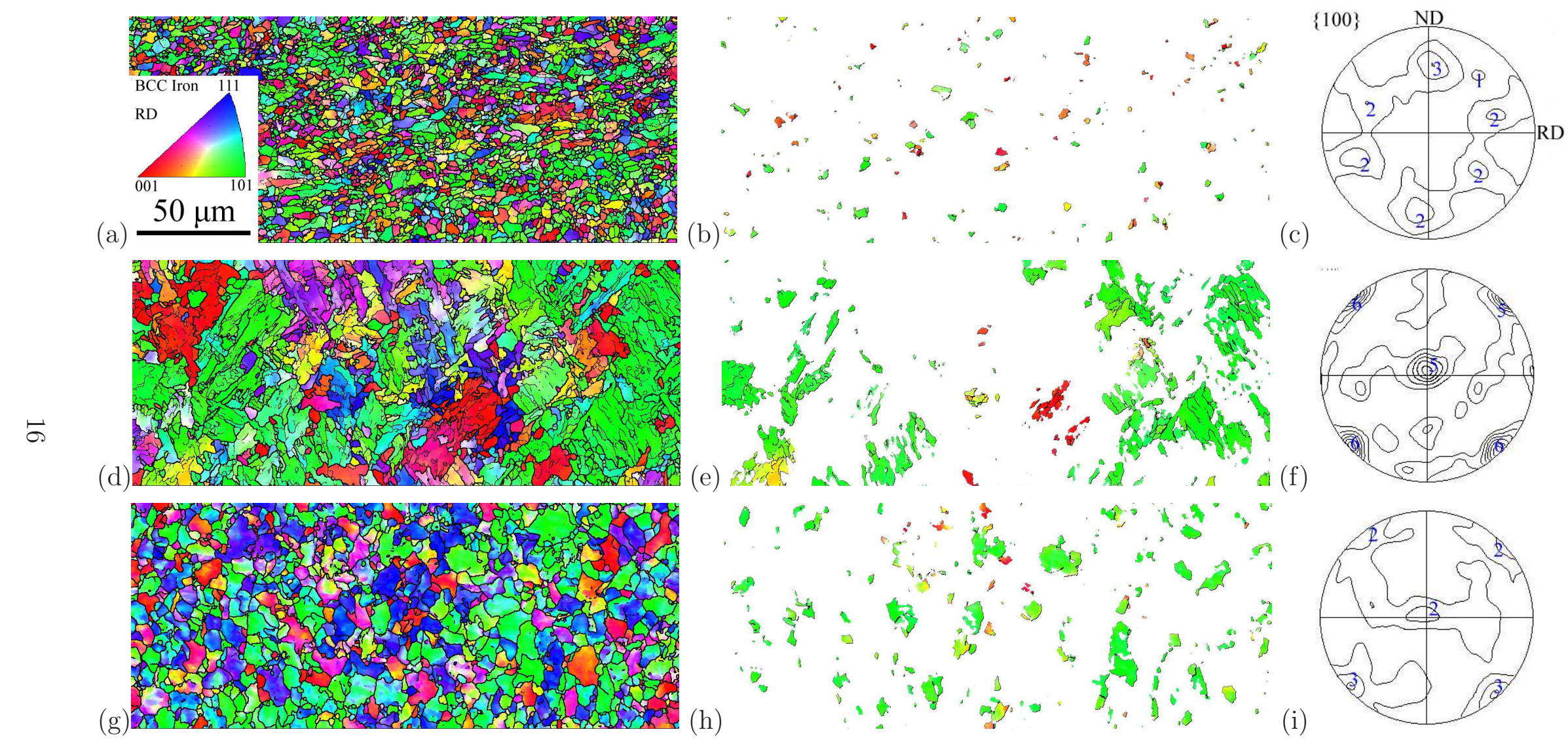

Figure 12: (a) Orientation image of base metal near the outer surface of the pipe with $14.8 \mathrm{~mm}$ wall-thickness. (b) Orientation image of grains in the same area of (a), oriented in the way that their $\{100\}$ planes are within $10^{\circ}$ to RD-ND surface. (c) Pole figure from the area of (a). (d)(e)(f) and (g)(h)(i) Equivalent images for the as-welded and the heat-treated weld junctions respectively. 


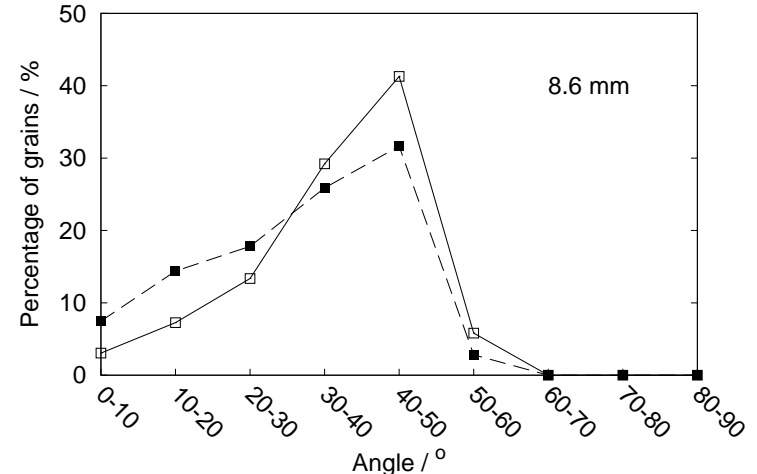

(a)

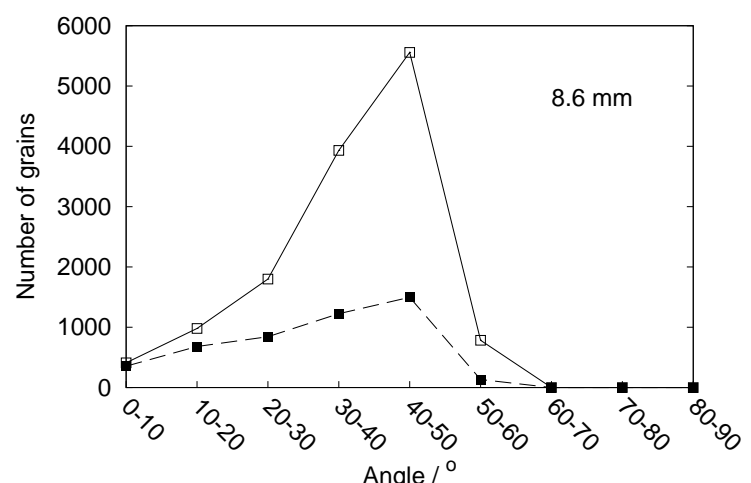

(c)

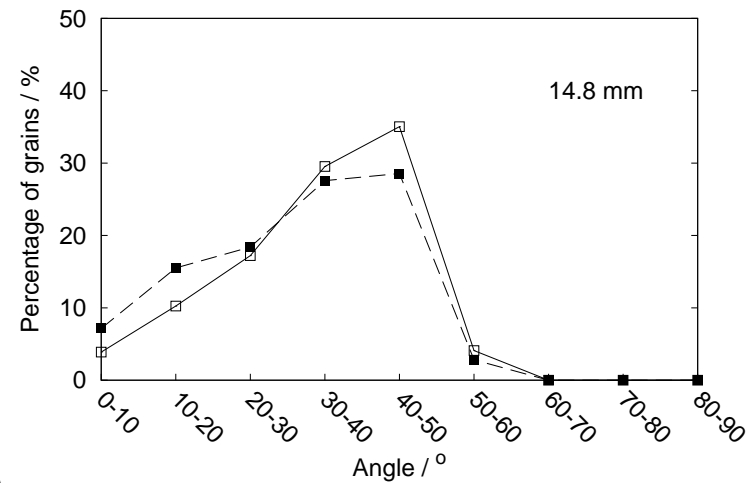

(b)

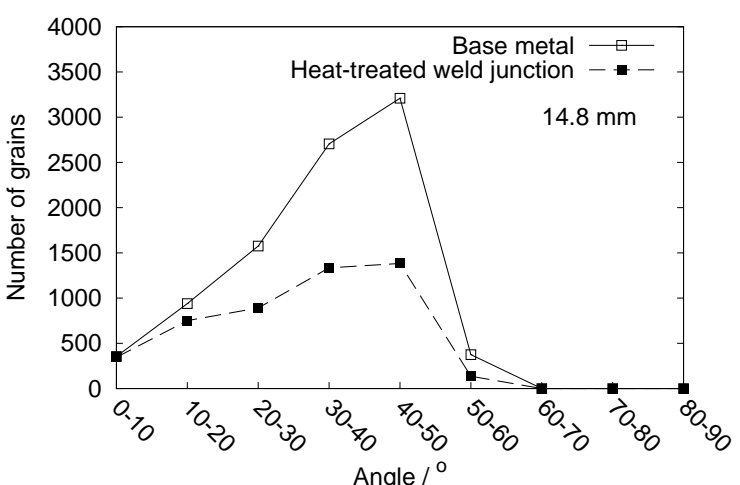

(d)

Figure 13: Distribution of the minimum angle between $\{100\}$ plane and the ND-RD surface for all the grains scanned by EBSD technique. 